\title{
ON GENERALIZED COUPLED FIXED POINTS WITH APPLICATIONS TO THE SOLVABILITY OF COUPLED SYSTEMS OF NONLINEAR QUADRATIC INTEGRAL EQUATIONS
}

\author{
MOHAMED ABDALLA DARWISH*,** AND KISHIN SADARANGANI ${ }^{* * *}$ \\ *Department of Mathematics, Sciences Faculty for Girls \\ King Abdulaziz University, Jeddah, Saudi Arabia \\ E-mail: dr.madarwish@gmail.com \\ ** Department of Mathematics, Faculty of Science \\ Damanhour University, Damanhour, Egypt \\ ***Departamento de Matemáticas, Universidad de Las Palmas de Gran Canaria \\ Campus de Tafira Baja, 35017 Las Palmas de Gran Canaria, Spain \\ E-mail: ksadaran@dma.ulpgc.es
}

\begin{abstract}
In this paper, we introduce the notion of generalized coupled fixed points and, as a consequence of Darbo's fixed point theorem associated to an abstract measure of noncompactness, we present a result about the existence of this class of coupled fixed points in Banach spaces. As an application, we investigate the existence of solutions for a class of coupled systems of nonlinear quadratic integral equations of Volterra type.

Key Words and Phrases: Measures of noncompactness, generalized coupled fixed point, coupled system, integral equation, fixed point theorem.
\end{abstract}

2010 Mathematics Subject Classification: 45G10, 45M99, 47H09.

Acknowledgment. The second author was partially supported by the project MTM2013-44357-P.

\section{REFERENCES}

[1] A. Aghajani, R. Allahyari, M. Mursaleen, A generalization of Darbo's theorem with application to the solvability of systems of integral equations, J. Comput. Appl. Math., 260(2014), 68-77.

[2] A. Aghajani, J. Banaś, N. Sebzali, Some generalizations of Darbo fixed point theorem and applications, Bull. Belg. Math. Soc. Simon Stevin, 20(2013), no. 2, 345-358.

[3] R.R. Akhmerov, M.I. Kamenskiǐ, A.S. Potapov, A.E. Rodkina, B.N. Sadovskiǐ, Measures of Noncompactness and Condensing Operators, Birkhäuser Verlag, Basel, 1992.

[4] A. Amini-Harandi, Coupled and tripled fixed point theory in partially ordered metric spaces with application to initial value problem, Math. Comput. Model, 57(2013), no. 9-10, 2343-2348.

[5] I. Banaś, K. Goebel, Measures of Noncompactness in Banach Spaces, Lecture Notes in Pure and Applied Mathematics, Vol. 60, Marcel Dekker, New York, 1980.

[6] J. Banaś, A. Martinon, Monotonic solutions of a quadratic integral equation of Volterra type, Comput. Math. Appl., 47(2004), 271-279. 
[7] J. Banaś, B. Rzepka, On local attractivity and asymptotic stability of solutions of a quadratic Volterra integral equation, Appl. Math. Comput., 213(2009), 102-111.

[8] V. Berinde, Coupled fixed point theorems for $\Phi$-contractive mixed monotone mappings in partially ordered metric spaces, Nonlinear Anal., 75(2012), no. 6, 3218-3228.

[9] J. Caballero, B. López, K. Sadarangani, On monotonic solutions of an integral equation of Volterra type with supremum, J. Math. Anal. Appl., 305(2005), no. 1, 304-315.

[10] S. Chandrasekhar, Radiative Transfer, Oxford Univ. Press, London, 1950.

[11] G. Darbo, Punti uniti in trasformazioni a codominio non compatto, Rend. Sem. Mat. Univ. Padova, 24(1955), 84-92.

[12] M.A. Darwish, K. Sadarangani, On existence and asymptotic stability of solutions of a functional-integral equation of fractional order, J. Convex Analysis, 17(2010), no. 2, 413-426.

[13] M.A. Darwish, S.K. Ntouyas, On a quadratic fractional Hammerstein-Volterra integral equation with linear modification of the argument, Nonlinear Anal., 74(2011), no. 11, 3510-3517.

[14] M.A. Darwish, J. Henderson, D. O'Regan, Existence and asymptotic stability of solutions of a perturbed fractional functional-integral equation with linear modification of the argument, Bull. Korean Math. Soc., 48(2011), no. 3, 539-553.

[15] M.A. Darwish, J. Henderson, Nondecreasing solutions of a quadratic integral equation of Urysohn-Stieltjes type, Rocky Mountain J. Math., 42(2012), no. 2, 545-566.

[16] M.A. Darwish, K. Sadarangani, Nondecreasing solutions of a quadratic Abel equation with supremum in the kernel, Appl. Math. Comput., 219(2013), 7830-7836.

[17] M.A. Darwish, J. Banaś, Existence and characterization of solutions of nonlinear VolterraStieltjes integral equations in two variables, Abstr. Appl. Anal. 2014, Art. ID 618434, 11 pp.

[18] S. Hu, M. Khavani, W. Zhuang, Integral equations arising in the kinetic theory of gases, Applicable Anal., 34(1989), 261-266.

[19] E. Karapinar, Couple fixed point theorems for nonlinear contractions in cone metric spaces, Comput. Math. Appl., 59(12)(2010), 3656-3668.

[20] C.T. Kelley, Approximation of solutions of some quadratic integral equations in transport theory, J. Integral Eq., 4(1982), 221-237.

[21] V. Lakshmikantham, L. Ćirić, Coupled fixed point theorems for nonlinear contractions in partially ordered metric spaces, Nonlinear Anal., 70(12)(2009), 4341-4349.

[22] R.W. Leggett, A new approach to the H-equation of Chandrasekher, SIAM J. Math., 7(1976), $542-550$.

[23] B.N. Sadovskiř, On a fixed point principle, (Russian), Funkcional. Anal. i Priloz, 1(1967), no. $2,74-76$

[24] B. Samet, Coupled fixed point theorems for a generalized Meir-Keeler contraction in partially ordered metric spaces, Nonlinear Anal., 74(12)(2010), 4508-4517.

[25] B. Samet, E. Karapinar, H. Aydi, V.C. Rajić, Discussion on some coupled fixed point theorems, Fixed Point Theory Appl., 50(2013), 12 pp.

[26] C.A. Stuart, Existence theorems for a class of nonlinear integral equations, Math. Z., 137(1974), 49-66.

Received: May 20, 2015; Accepted: March 1st, 2016. 